\title{
ARTICLES \\ A DISCRETE TIME MODEL FOR PRICING TREASURY BILLS, FORWARD, AND FUTURES CONTRACTS*
}

\author{
By I. G. Morgan and E. H. Neave \\ Queen's University School of Business \\ Kingston, Ontario K7L $3 N 6$
}

\begin{abstract}
This paper develops a discrete time model for valuing treasury bills and either forward or futures contracts written against them. It provides formulae for bill prices, forward prices, futures prices, and their conditional variances and risk premiums. The interest rate process is described by a multiplicative binomial random walk whose features conform to some principal characteristics of observed processes. Initial forward rates are constrained to match initially observed term structure data.
\end{abstract}

\section{INTRODUCTION}

This paper uses a discrete time multiplicative binomial model of the spot interest rate process to derive pricing formulae for treasury bills, and forward and futures contracts written against them. All results are developed under assumptions of zero arbitrage profits. The model is constrained to match the initial term structure of interest rates, and uses an empirically plausible interest rate process.

The model explicitly states the theoretical and empirical importance of initially estimated forward rates, bond maturity dates, and forward and futures contract delivery dates. We find pricing formulae and time dependent expressions for the conditional variance and conditional risk premiums of bill prices, forward prices and futures prices. Finally, we use a property of binomial processes to relate conditional variances and risk premiums, and hence provide theoretical support for relations used in the empirical literature (ENGLE [1982]; ENGLE, LILIEN and RoBINS [1987]).

\subsection{Organization of paper}

The paper is organized as follows. The rest of this section reviews relevant literature. The model and its underlying assumptions are described in Section 2, which also specifies how the spot rate and the term structure evolve. Section 3

\footnotetext{
* Earlier versions of this paper were presented to the Inaugural Meetings of the Northern Finance Association, Ottawa, Canada, September 23-24, 1989, and to the First AFIR International Colloquium of the International Actuarial Association, Paris, April 23-27, 1990. We thank the editor and referees for constructive suggestions.
}

ASTIN BULLETIN, Vol. 23, No. 1, 1993 
develops formulae for treasury bill prices and shows how the conditional martingale probabilities are restricted by initial assumptions regarding the term structure. Section 4 develops formulae for consistently calculating forward prices, their conditional variances, and conditional risk premiums. Section 5 does the same for futures contracts, and Section 6 concludes.

\subsection{Theoretical literature}

BLACK [1976] prepares the groundwork for the theory of commodities futures pricing. CoX, INGERSOLl and Ross [1981], FRENCH [1981], JARROW and OlDFIELD [1981] and RICHARD and SUNDARESAN [1981], all develop important properties of forward and futures contracts and prices. Our discrete time model is based on the approaches to options pricing used by Cox, Ross and RUBINSTEIN [1979] and by CoX and RUBINSTEIN [1985].

Our approach is analytically more tractable than Ho and LEE [1986], Ritchken and BoENAWAN [1990], or RitCHKEN and SANKARASUBRAMANIAN [1990]. In addition, we specify empirically plausible interest rate processes rather than specifying convenient processes and then constraining them, as do both Ho and Lee and Ritchken and Sankarasubramanian. Like PEDERSEN, SHIU and THORLACIUS [1989] we induce shifting yield curve shapes, but also provide more explicit results than theirs. Our model, like that of TURnBulL and MILNE [1991], can be expanded to find bill and futures pricing formulae for interest rate processes with varying degrees of mean reversion (cf. MoRGAN and NeAve [1992]). While both models can derive prices for many different kinds of derivative securities, Turnbull and Milne price options, while we price forward and futures contracts.

We also obtain more explicit results than the more distantly related works of BLISS and RONN [1989] and of Kishimoto [1989]. Bliss and Ronn offer a trinomial version of the Ho and Lee model, while Kishimoto models both interest rate and asset price uncertainty.

In some senses, our model is also more tractable than the continuous time models of HEATH, JARROW and MORTON [1990, 1992] (hereafter HJM) and of JAMSHIDIAN [1989]. In contrast to HJM and in common with Jamshidian, our forward interest rate process can be extended to incorporate mean reversion; cf. Morgan and Neave [1992]. In contrast to both HJM and Jamshidian [1989], we find formulae for the martingale probabilities that are consistent both with the data we use and with the form of stochastic process modelled. Our model also bears similarities to HJM [1990a] discrete time model, but HJM focus mainly on the existence of the martingale while we focus mainly on interpretive issues. Moreover, we find conditions for uniqueness of the martingale which HJM [1990a] do not. Finally, we establish analytical relations between instruments' risk premiums and their prices' conditional variance that have not previously been obtained in any of the other models mentioned above.

JACOBS and JONES [1980] report one of the first empirical studies of treasury bill futures prices. Their approach of comparing model predicted with observed 
prices has since become standard and is discussed in such works as BLACK, Derman and Toy [1990], Hull and White [1990], RitchKen and SANKARASUBRAMANIAN [1990] and JAMSHIDIAN [1991]. Our model can be used in this way as well, but it has another advantage. It uses binomial model relations between risk premiums and conditional variances in conducting tests, and thus need not estimate many of the parameters used in the standard approach; cf. Morgan and NeAve [1992]. As HJM [1990a, p. 420] observe, estimates based on martingale probabilities, as in Ho and Lee, can lead to instabilities.

Our pricing theory does not incorporate delivery options, the effects of which are considered in GAY and Manaster [1984], Hemler [1990], Kane and MARCUS [1986] and BoYLE [1989]. We could incorporate delivery options quite readily in expanded versions of our model, but the data we have tested so far (cf. Morgan and NEAVE [1992]) are for contracts without important delivery options.

\section{ANALYTICAL MODEL}

Our model is based on a discrete time approach to options pricing originally proposed by Sharpe. We follow the development in Cox and RUBINSTEIN [1985].

\subsection{Useful mode properties}

We use spot interest rates as a state variable, allowing the term structure to evolve under the same potential set of constraints as do other who follow Ho and LEE [1986]. However as shown below, we choose martingale probabilities which: retain the originally assumed interest rate process, maintain consistency with the data, and ensure the absence of arbitrage opportunities.

In contrast, Ho and Lee first model the interest rate process and then assume constant martingale probabilities, thus altering their original mode of interest rate evolution to ensure consistency with the data; cf. Ho and LEE [1986, eqn. (A.6)]. In further contrast to Ho-Lee and others, our model does not permit negative spot interest factors (where an interest factor is one plus an interest rate), a useful feature which also suggests a way to eliminate negative interest rates!

\subsection{The interest factor process}

Let $R_{t}$ be the riskless spot factor; i.e., one plus the one-period riskless rate. Let $R_{0}$ be the initial spot factor, and $\left\{R_{t}\right\}, t \in I_{1}^{T} \equiv\{1,2, \ldots, T\}$, a (deterministic) series of one period forward factors given by data available at time 0 . Throughout the paper, it will be supposed that the time horizon $T$ is greater than the longest bond maturity $M$ which we wish to study explicitly.

\footnotetext{
1 To eliminate the possibility of negative interest rates, an interest factor $R_{t}$ can be modelled to evolve as $\left(R_{t}\right)^{u(t)}$ in the event of an interest rate increase, and as $\left(R_{t}\right)^{1 / u(t)}$ in the event of an interest rate decrease, where $u(t)$ is a suitably chosen function (whose values are greater than unity).
} 
The forward factors can be determined from government treasury bill data at time zero. For example, if $B_{0}(1)$ and $B_{0}(2)$ are the time zero prices of the one and two period zero coupon bonds respectively ${ }^{2}$, then by the term structure of interest rates

$$
B_{0}(1)=1 / R_{0}
$$

and

$$
B_{0}(2)=1 /\left(R_{0} \cdot R_{1}\right)
$$

so that

$$
R_{1}=B_{0}(1) / B_{0}(2) .
$$

The remaining values of the $\left\{R_{t}\right\}$ can be determined similarly.

The forward factors become spot factors as they are realized. Using the perspective of time zero, we assume the future spot factors will evolve stochastically about the $\left\{R_{t}\right\}$ according to a multiplicative factor $u>1$. If the time $t$ spot factor is $u^{j} R_{t}$,

$$
j \in J_{t} \equiv\{t, t-2, t-4, \ldots,-t+2,-t\}
$$

$t \in I_{1}^{T}$, the $t+1$ spot factor will be either $u^{j+1} R_{t+1}$ or $u^{j-1} R_{t+1}$, the possible realizations occurring with probabilities $p$ and $1-p \equiv q$ respectively. Between times $t$ and $t+1$ the spot factor must move either up or down, but it can return to the same level every two periods. The successive spot factors thus evolve according to:

$$
S_{t+1}=R_{t+1} S_{t} U / R_{t},
$$

where $S_{t}$ is the spot factor at time $t$, and $U$ is a random variable which assumes the values $u>1$ with probability $p$ and $u^{-1}$ with probability $q$. Since $S_{0} \equiv R_{0}$, it follows immediately from (2.2.2) that

$$
S_{t+1}=R_{t+1} U_{t+1} \text {, }
$$

where $U_{t+1}$ is the random variable ${ }^{3}$ generated by $t+1$ successive realizations of $U$.

The mean and variance of $U$ are respectively given by

$$
\begin{aligned}
& E(U)=p u+q / u \quad \text { and } \\
& V(U)=p q\left[\left(u^{2}-1\right) / u\right]^{2} .
\end{aligned}
$$

The drift of the process (2.2.2) is determined ${ }^{4}$ by $E(U)$. If $E(U)=1$, the process has a constant mean ${ }^{5}$, apart from any changes in $R_{t}$. The spot factor

2 The effect of changing interest rates is left implicit in the notation of this section and in that of the Appendix. In the rest of the paper, it is helpful to recognize interest rate effects explicitly.

${ }^{3}$ For example, $U_{3}$ has the outcomes $u^{3}, u, u^{-1}$, and $u^{-3}$, with probabilities $p^{3}, 3 p^{2} q, 3 p q^{2}$, and $q^{3}$ respectively.

${ }^{4}$ Apart from the influence of the parameters $R_{t}$.

${ }^{5}$ We are grateful to a referee for pointing out that if $E(U) \leq 1$ (and $u \neq 1$ ), then $U_{t} \rightarrow 0$ with probability 1 by the supermartingale convergence theorem. If in addition $R_{t}$ is bounded, then $S_{t}<1$ from some random point onwards, and from that point spot rates are negative. Thus to have a sensible model we want $E(U)>1$. 
process has a lower bound of zero and ${ }^{6}$, for finite values of $u, t$ and $R_{t}$, a finite upper bound of $u^{t} R_{t}$.

Finally, the conditional variance of the spot factor process is determined as follows. Recalling (2.2.3), let $Z$ be a binomial random variable assuming the values $x$ and $y$ with probabilities $p$ and $q=1-p$ respectively, and suppose $y>x$. Then since

$$
Z^{*}=(Z-x) /(y-x)
$$

is a standardized random variable whose outcomes 0 and 1 occur with probabilities $p$ and $q$ respectively,

$$
V(Z)=V\left(Z^{*}\right)(y-x)^{2}=p q(y-x)^{2} .
$$

Applying (2.2.6) to (2.2.2),

$$
V_{t}\left(u^{j}\right)=p q\left[\left(u^{j+1}-u^{j-1}\right) R_{t+1}\right]^{2} .
$$

For any fixed value of $t, V_{t}$ is an increasing function of $j$.

\section{BILL PRICES AND INTEREST RATES}

We use martingale methods to derive bill prices from the interest rate process ${ }^{7}$. We ensure consistency with observed data by finding martingale probabilities such that the time zero bill prices calculated under the martingale equal their time zero observed values, a procedure that involves as many restrictions on the martingale probabilities as there are bond maturities ${ }^{8}$.

The foregoing restrictions also ensure the absence of arbitrage profits for trading in any combination of bonds. For, assuming the originally observed bill prices reflect an equilibrium, they offer no arbitrage opportunities at time zero. Moreover, no combination of outstanding bonds can offer arbitrage opportunities at any time strictly between zero and their maturity, because those prices are all calculated using exactly the same interest rate process and martingale probabilities ${ }^{9}$. Indeed, the conditions derived below correspond to condition (15) in HEATH, JARROW and MORTON [1990a], who focus on how the forward rate process must be restricted if the martingale is to exist.

${ }^{6}$ If $R_{t}$ is constant, the process converges to the lognormal; see for example Cox and RUBINSTEIN [1985].

7 It should be noted that while it is customary to refer to conditional martingale probabilities, these numbers are neither martingales nor probabilities. The number $p_{i}$, which is defined to be the conditional martingale probability denoting an upward move in the spot rate, is not the same as the actual probability $p$ of an upward move in the spot rate. Rather, the $p_{t}$, are numbers which add to unity like probabilities. They can be used in risk neutral valuation procedures because their existence is equivalent to the assumption of no arbitrage profit opportunities. Finally, the martingale itself is the constant mean stochastic process describing bond prices, after they have been normalized to remove the effects of the risk free interest rate. For a full discussion, see HUANG and LiTZENBERGER [1988, chapter 8].

${ }^{8}$ However, since as will be shown the $T+2$ 'nd condition is just that $p_{T+1}+q_{T+1}=1$, there are really only $T+1$ nontrivial conditions.

9 The assumption of zero arbitrage profits is both necessary and sufficient for existence of a martingale permitting prices to be found using expected value calculations; cf. HUANG and LITZENBERGER [1988, 196-203; 242-244]. 
The rest of this section shows how our term structure evolves, as in Ho and Lee, from initially specified values, and how that affects bill prices. However, as summarized in Section 3.5, Ho and Lee can use constant martingale probabilities because they restrict their initially specified interest rate process. In so doing, they do not analyze the implications for their orginally chosen interest rate process. In contrast, we use time dependent martingale probabilities in order not to alter the initially specified process. Rather, we state directly the spot interest rate process used in our model and find martingale probabilities which conform to it and the data.

\subsection{Interest rates, bill prices, and the martingale}

Given the time zero estimates of the forward factors $\left\{R_{t}\right\}, t \in I_{1}^{T}$, all bills have a time zero value determined by ${ }^{10}$ the geometric mean of $R_{0}$ and the $\left\{R_{t}\right\}$. Let $B_{t}(j, M)$ represent the market price at time $t$, when the spot rate is $u^{j} R_{t}, j \in J_{t}$, $t \in I_{0}^{M-1}$; of a bill with maturity $M$. Finally, let all bills have a value of unity at maturity. A one period bill's value is then related to the prevailing risk free (spot) rate by

$$
B_{M-1}(j, M)=1 / u^{j} R_{M-1} .
$$

We denote the (conditional) martingale probabilities associated with an interest factor increase by $p_{t}$, and by $q_{t} \equiv 1-p_{t}$ with a decrease. Under the martingale, for $t<M-1$,

$$
B_{t}(j, M)=\left[p_{t} B_{t+1}(j, M)+q_{t} B_{t+1}(j+2, M)\right] / u^{j} R_{t} .
$$

In Section 3.3, we find formulae for bill prices of any maturity. However, before doing so we wish to explore, through an example, the implied restrictions on the martingale probabilities when the model builder seeks consistency between time zero observed values and the model itself ${ }^{11}$.

\subsection{Exemple}

The martingale probabilities may exhibit state dependency, time dependency, or both. If the model builder wishes the martingale probabilities to have certain properties, then only certain interest rate processes can be consistent with both the initial data and the absence of arbitrage opportunities; cf. HJM [1990a]. To see this, consider the prices of the three bills with maturities up to $M=3$. For consistency with the initial term structure, the time zero prices of bills must satisfy

$$
B_{0}(0, M)=1 / \prod_{t=0}^{M-1} R_{t} ; \quad M \in\{1,2,3\} .
$$

10 The continuous time literature usually establishes the existence of the martingale but does not discuss its exact relation to the model and the data; HJM [1992] is an exception. Indeed, HJM search for methods that eliminate the need to calculate or to estimate the martingale probabilities. The discrete time literature usually assumes constant martingale probabilities; again HJM [1990a] is an exception.

11 Dybvig [1989] notes that several authors in effect force the term structure to fit the model. 
Under the martingale, the one period bill price must also satisfy

$$
B_{0}(0,1)=\left[p_{0}+q_{0}\right] / R_{0},
$$

since the maturity value of the bill is unity whichever interest rate obtains at time 1 .

The value of the one period bill does not restrict $p_{0}$, but the two period bill price must satisfy both

$$
B_{0}(0,2)=\left(1 / R_{0}\right)\left\{\left[p_{0} /\left(u R_{1}\right)\right]+\left[q_{0} /\left(u^{-1} R_{1}\right)\right]\right\}
$$

and (3.2.2). Since $p_{0}+q_{0}=1$, the solutions are

$$
p_{0}=u /[u+1], \quad q_{0}=1 /[u+1] .
$$

Finally, consider finding the time zero price of the bill maturing at $M=3$. At time 3 its value is unity, and at time 2 it can assume any one of the three values

$$
B_{2}(j, 3)=1 / R_{2} u^{2-j} ; \quad j \in\{0,2,4\}
$$

To recognize possible state dependence of the martingale probabilities $p_{t}, t>0$, denote the martingale probability for an upward move from state $j$ at time $t$ by $p_{t}(j)$. Continuing the calculation by backward induction, at time 1 the bill's two possible values are then

$$
\begin{aligned}
B_{1}(0,3) & =\frac{p_{1}(0)}{u R_{1}} B_{2}(0,3)+\frac{q_{1}(0)}{u R_{1}} B_{2}(2,3) \\
& =\frac{p_{1}(0)+u^{2} q_{1}(0)}{u^{3} R_{1} R_{2}},
\end{aligned}
$$

and

$$
\begin{aligned}
B_{1}(2,3) & =\frac{p_{1}(2)}{u^{-1} R_{1}} B_{2}(2,3)+\frac{q_{1}(2)}{u^{-1} R_{1}} B_{2}(4,3) \\
& =u \frac{p_{1}(2)+u^{2} q_{1}(2)}{R_{1} R_{2}}
\end{aligned}
$$

Finally at time zero,

$$
B_{0}(0,3)=\left[p_{0} / R_{0}\right] B_{1}(0,3)+\left[q_{0} / R_{0}\right] B_{1}(2,3),
$$

and the same bill price must also satisfy (3.2.2). Substituting (3.2.2) and (3.2.5) in (3.2.8) gives

$$
1=\frac{p_{1}(0)+u^{2} q_{1}(0)+u^{3}\left[p_{1}(2)+u^{2} q_{1}(2)\right]}{u^{2}(u+1)}
$$


which simplies to

$$
p_{1}(0)=u^{2} q_{1}(2) .
$$

Given $u, R_{0}, R_{1}, R_{2}$, the valuation problem consists of five equations; namely, (3.2.4), (3.2.9) and

$$
\begin{gathered}
p_{0}+q_{0}=1 ; \\
p_{1}(j)+q_{1}(j)=1 ; \quad j \in\{0,2\} .
\end{gathered}
$$

Two of the five equations are used to solve for $p_{0}$ and $q_{0}$. Since there are two unknown binomial probabilities at time 1 , we need one of the following three equivalent conditions to resolve the indeterminacy illustrated by (3.2.9):

$$
\begin{gathered}
p_{1}(0)=p_{1}(2), \\
B_{1}(2,3) / B_{1}(0,3)=u^{4}, \\
p_{1}(0)=u^{3} /\left[1+u^{3}\right] .
\end{gathered}
$$

If as below we use (3.2.10) and assume the martingale probabilities at time 1 are state independent, the same choice implies both (3.2.11) and (3.2.12). Note finally that with bonds maturing at dates 1,2 and 3 our martingale probabilities must satisfy two constraints, expressed in the form of bond valuation equations. This property extends to $T+1$ conditions in the next section, where there are $T+2$ bonds.

\subsection{Bill prices for longer maturities}

The bill market is dynamically complete for a time horizon of $T$ if at time zero bills with maturities of $T+1$ and $T+2$ are available (HUANG and LITZENBERGER [1988]). As in Section 3.2, we assume either of the following two equivalent conditions to eliminate remaining indeterminacies:

$$
p_{t}(j)=p_{t} ; \quad j \in J_{t} ; \quad t \in I_{1}^{T+1},
$$

or

$$
\frac{B_{t}(j+2, M)}{B_{t}(j, M)}=v_{t, M} \equiv \prod_{k=t}^{M-1} u^{2} .
$$

Then for $t>2$, backward induction procedures exactly like those of Section 3.2 show that

$$
p_{t}=u^{2 t+1} /\left[1+u^{2 t+1}\right]
$$

We next simplify notation by suppressing the maturity $M$ unless clarity requires otherwise. In particular, we write $v_{t, M}$ as $v_{t}$, and we also define

$$
v_{M, M} \equiv v_{M} \equiv 1 \text {. }
$$


Then in analogy to (3.1.2), the bill prices can be written recursively as 12

$$
B_{t}(j)=\left[p_{t} B_{t+1}(j)+q_{t} B_{t+1}(j+2)\right] / u R_{t} .
$$

Then (3.3.5) and

$$
B_{t+1}(j+2)=v_{t+1} B_{t+1}(j) ;
$$

$j \in J_{t}, t \in I_{1}^{M-1}$, can be used in the backward induction arguments of Section 3.2 to obtain

$$
B_{t}(0)=\prod_{k=t}^{M-1} \frac{\left[p_{k}+v_{k+1} q_{k}\right]}{u^{k} R_{k}} ;
$$

for $j=t$ and $t \in I_{0}^{M-1}$. While equation (3.3.7) expresses the bill price in terms of the maximum possible interest rate one period prior to the bill's maturity, it can be used in conjunction with (3.3.6) to express the bill price in terms of any interest rate realization.

Since at time $t$ and in state $j$ the term structure is defined by the bill price formulae (3.3.7), the derivation of the bill prices implies the term structure evolves in a particular manner. For example, the interest factor terms for two bills maturing in successive periods are given by $1 / B_{t}(j, t+1)$ and $\left[1 / B_{t}(j, t+2)\right]^{1 / 2}$. Moreover, the one period forward factor between times $t+1$ and $t+2$, conditional on reaching time $t$ and state $j$, is ${ }^{13}$

$$
B_{t, t+1}(j) / B_{t, t+2}(j) \text {. }
$$

\subsection{Conditional risk premium and variance}

If the process is in state $j$ at time $t, B_{t+1}(j)$ occurs with probability $p$ and $B_{t+1}(j+2)$ with probability $q$. Then by (3.3.6) the conditional risk premium of the bill price is

$$
\begin{aligned}
P_{B, t}(j) & =E_{t} B_{t+1}(J)-B_{t}(j) u R_{t}, \\
& =\left(q v_{t+1}+p\right) B_{t+1}(j)-u_{j} R_{t},
\end{aligned}
$$

which under the martingale becomes

$$
\begin{aligned}
P_{B, t}(j) & =\left(q v_{t+1}+p\right) B_{t+1}(j)-\left(q_{t} v_{t+1}+p_{t}\right) B_{t+1}(j) \\
& =\left(q-q_{t}\right)\left(v_{t+1}-1\right) B_{t+1}(j) .
\end{aligned}
$$

Similarly, taking

$$
y=v_{t+1} B_{t+1}(j) \quad \text { and } \quad x=B_{t+1}(j),
$$

12 Rewriting (3.3.5) to express the martingale in terms of bond prices shows how the price evolution would be constrained by assuming the martingale probability is constant. That is, (3.3.5) says that a constant martingale probability $p^{*}$ must satisfy

$$
p^{*}=\left[u^{j} R_{t} B_{t}(j)-u^{j+1} B_{t+1}(j)\right] /\left[1-u^{j+1} B_{t+1}(j)\right],
$$

for all $t$ and for all $j$. In effect, Ho-LEE [1986] impose this constraint; cf. their Appendix eqn. (A6).

13 Since by (3.3.2) $v_{t}$ depends on $M$, the forward rate formulae for individual bonds are also maturity dependent. 
and applying (2.2.6) to (3.3.7), shows that the conditional variance of the bill price is

$$
V_{B, t}(j)=p q\left(v_{t+1}-1\right)^{2} \cdot\left[B_{t+1}(j)\right]^{2} .
$$

But then combining (3.4.1) and (3.4.2),

$$
K_{B, t}^{*} \equiv P_{B, t}^{*}(j) /\left[V_{B, t}^{*}(j)\right]^{1 / 2}=\left(p_{t}-p\right) /(p q)^{1 / 2} .
$$

The risk premium in (3.4.1) is positive if and only if ${ }^{14} p_{t}>p$. Moreover, (3.4.3) shows that the conditional risk premium and the conditional standard deviation are strictly proportional at any time $t$, offering theoretical support for the ARCH-M model used by ENGE, LILIEN and RoBins [1987]. Finally it is evident from the derivation that (3.4.3) is a general feature of binomial models, rather than being specific to the model of this paper ${ }^{15}$.

\subsection{Relation to Ho-Lee type models}

It is instructive to interpret the formulae of Section 3.2 using the perturbation functions of Ho and LEE [1986]. In our notation, equations (1) and (2) of BLISS and RoNN [1989] summarize the relations between the perturbation functions

$$
h(M-t), \quad h^{*}(M-t)
$$

as

$$
\begin{gathered}
B_{t+1}(j)=B_{t}(j) u^{j} R_{t} h(M-t), \\
B_{t+1}(j+2)=B_{t}(j) u^{j} R_{t} h^{*}(M-t) .
\end{gathered}
$$

Using (3.3.6) to rewrite (3.5.1) gives

$$
h(M-t)=1 /\left[p_{t}+v_{t+1} q_{t}\right],
$$

and with further use of (3.4.1), (3.5.2) gives

$$
h^{*}(M-t)=v_{t+1} /\left[p_{t}+v_{t+1} q_{t}\right] \text {. }
$$

Comparison with BLISS and RoNN [1989, eqn. (3)] shows that $p_{t}$ plays a role analogous to $\pi$ while $v_{t+1}$ plays a role analogous to $\delta^{M-t}$. Ho and LEE [1986], Bliss and Ronn [1989], Kishimoto [1989], RitchKen and Boenawan [1990] and RitchKen and SaNkARASUBRAMANian [1990] all treat $\pi$ as constant, and independent of $\delta$, basing their argument on Ho, LEE [1986, eqn. (A6)]. But none of these authors explicitly considers the implication of the constant $\pi$ assumption for the originally chosen interest rate process ${ }^{16}$, and for this reason

\footnotetext{
${ }^{14}$ We cannot specify the relationship between $p$ and $p_{t}$ without a general equilibrium analysis, but if agents are risk averse we know that $p_{t}>p$.

${ }_{15}$ We are grateful both to an unnamed referee and to David Laughton for pointing this out to us. Note also that using this condition we can avoid the need to estimate martingale (pseudo) probabilities. This is advantageous since as HJM [1990a, p. 420] point out, estimating the pseudo probabilities can lead to instabilities.

${ }^{16}$ The implications are for the process as distinct from its time zero values. Ho-Lee's orginal term structure is consistent with the data, but the stochastic process describing its evolution is not considered explicitly after assuming $\pi$ to be constant. See aso note 10 above.
} 
it is difficult to assess how the form of interest rate evolution they use compares with estimated processes.

\section{FORWARD PRICES}

This section values develops expressions for forward prices, their conditional variances, and risk premiums. A forward contract is a commitment to buy or to sell an asset at some fixed future time, for an initially specified price called the forward price. A forward commitment to buy is called a long position, a forward commitment to sell a short position. Typically, a forward contract is written at a forward price which makes its present value equal to zero. A long position in a forward contract leads to a capital gain if on the contract maturity date (in futures market parlance, the delivery date) the underlying asset has a spot price in excess of the forward price, and to a capital loss if the reverse is true.

\subsection{Recursive calculation of forward prices}

Let $G_{t}(j, T, M)$ be the forward price at time $t$, when the spot factor is $u^{j} R_{t}$, on a contract written at time $t$, with delivery date $T$, against a bill maturing at time $M \geq T$. On the delivery date, the forward price equals the value of the underlying instrument; cf. CoX, INGERSOLL, Ross [1981]. Therefore,

$$
G_{T}(j, T, M)=B_{T}(j, T, M) .
$$

As before, the arguments $T$ and $M$ will be suppressed whenever no ambiguity results, and the forward price will usually be written $G_{t}(j) ; t \in I_{0}^{T}$; $j \in J_{t}$.

Next, let the value at time $t$ of a forward contract written at time 0 , with exercise (delivery) price $X_{T}$, and when the spot factor is $u^{j} R_{t}$, be defined as $F_{t}\left(j, X_{T}, T, M\right)$. As before, arguments will be suppressed unless needed for clarity, and the value of the forward contract will normally be written ${ }^{17}$ $F_{t}\left(j, X_{T}\right)$.

Consider first the problem of valuing a forward contract with an arbitrary delivery price; it will then be easy to calculate the forward price for that contract. Proceeding by backward induction, on the delivery date the contract value is the difference between the bond price and $X_{T}$, the delivery price. Thus, if the interest factor is $u^{T} R_{T}$ :

$$
F_{T}\left(T, X_{T}\right)=B_{T}(T)-X_{T}=\left[1 /\left[u^{T} R_{t}\right]^{M-T}\right]-X_{T} .
$$

17 We shall show below how the notation can accommodate forward contracts written at arbitrary times $t$. It is convenient to define the value of the forward contract as well as the forward price so that bond prices, forward prices, and futures prices can all be related using the same methodology. The notation for forward and futures prices $\left(G_{t}(j)\right.$ and $H_{t}(j)$ respectively) is consistent with CoX, INGersold, Ross [1981], and $G_{t}(j)$ is the special value of $X_{T}$ such that the value of the forward contract is zero when it is written; cf. JARRow and OLDFIELD [1981]. 
Then noting that $(4.1 .2)$ can be written

$$
F_{T}\left(T, X_{T}\right)=B_{T}(T, T, M)-B_{T}(T, T, T) X_{T}
$$

it follows immediately from the results of Section 3.2 that

$$
F_{t}\left(t, X_{T}\right)=B_{t}(t, T, M)-B_{t}(t, T, T) X_{T}
$$

and in particular

$$
F_{0}\left(0, X_{T}\right)=B_{0}(0, T, M)-B_{0}(0, T, T) X_{T} .
$$

Next, equation (4.1.5) implicitly defines $G_{0}(0)$ by the condition

$$
F_{0}\left(0, G_{0}(0)\right)=0 \text {. }
$$

That is,

$$
G_{0}(0)=B_{0}(0, T, M) / B_{0}(0, T, T) ;
$$

cf. JARrow and OldFiELD [1981, p. 381, eqn. (13)].

\subsection{Conditional variance of forward prices}

The forward price on a contract written at time $t$ does not change before the contract delivery date, time $T$. However, new contracts can be written at times $s>t$, and the conditional variance of forward prices refers to the possible variations in the prices on these new contracts, which will be written to reflect the newly prevailing time and interest factor environment.

For theoretical purposes, assume a new contract is written at each point in time $s$, and that all contracts have the same delivery date $T$. Given the forward price $G_{t}(j)$, the forward price at time $t+1$ is either $G_{t+1}(j+1)$, with probability $p$, or $G_{t+1}(j-1)$ with probability $q$. Then using methods similar to those of Section 3 and using (4.1.7), (4.2.1) can be rewritten as

$$
V_{G, t}^{*}(j)=\frac{p q\left(u^{2(M-t-1)}-1\right)^{2} \cdot\left[G_{t}(j)\right]^{2} \cdot\left(p_{t}+u^{2(T-t-1)} q_{t}\right)^{2}}{\left(p_{t}+u^{2(M-t-1)} q_{t}\right)^{2}} .
$$

Denoting the conditional variance of the rate of change of the forward price by $V_{G, t}^{*}(j)=V_{G, t}(j) /\left[G_{t}(j)\right]^{2}$, it follows immediately from (4.2.2) that

$$
V_{G, t}^{*}(j)=\frac{p q\left(u^{2(M-t-1)}-1\right)^{2} \cdot\left(p_{t}+u^{2(T-t-1)} q_{t}\right)^{2}}{\left(p_{t}+u^{2(M-t-1)} q_{t}\right)^{2}},
$$

independent of $j$.

\subsection{Conditional risk premiums in forward prices}

Define the conditional risk premium in a forward price by

$$
P_{G, t}(j)=E_{t}\left\{G_{t+1}(J)\right\}-G_{t}(j)
$$


where $E_{t}$ denotes the time $t$ conditional expectation of the time $t+1$ forward price.

Condition (4.3.1) can be rewritten

$$
P_{G, t}(j)=\left[\frac{\left(p+u^{2(M-t-1)} q\right) \cdot\left(p_{t}+u^{2(T-t-1)} q_{t}\right)}{\left(p_{t}+u^{2(M-t-1)} q_{t}\right)}-1\right] G_{t}(j) .
$$

An expression for the risk premium in rate of return form can also be found using

$$
P_{G, t}^{*}(j)=P_{G, t}(j) / G_{t}(j)
$$

\subsection{Conditional risk premium and standard deviation}

As with bill prices, a proportional relationship between $P_{G, t}^{*}(j)$ and $\left[V_{G, t}^{*}(j)\right]^{1 / 2}$ by using (4.3.3) and (4.2.2) to define an appropriate proportionality constant :

$$
P_{G, t}^{*}(j) /\left[V_{G, t}^{*}(j)\right]^{1 / 2} \equiv K_{G, t}^{*} .
$$

After simplification

$$
K_{G, t}^{*}=\frac{p_{t}-p}{(p q)^{1 / 2}}+\frac{q_{t}\left(u^{2(T-t-1)}-1\right)\left(1+u^{2(M-t-1)} q_{t}\right)}{(p q)^{1 / 2}\left(u^{2(M-t-1)}-1\right)\left(1+u^{2(T-t-1)} q_{t}\right)} .
$$

The standardized risk premium for the forward price is a more complex expression than for the bond because the forward price is the ratio of two bond prices, and this ratio reflects the influence of both bonds' prices.

\section{FUTURES PRICES}

This section develops expressions for futures prices, their conditional variances, and risk premiums. A futures contract can be thought of as a series of forward contracts, so designed that any capital gains or losses are realized on a day to day basis. To see this, consider the value of a long forward contract, as described at the beginning of Section 4, after one day of its life has elapsed. If the asset has risen in value over the day, the value of the forward contract will have increased from zero. With a forward contract any such capital gain (or loss) goes unrealized until its delivery date, when any capital gains or losses are realized in a single transaction.

However if the contract is a futures contract written on exactly the same terms, then at the end of day one the holder of the long position is paid the capital gain, or pays the capital loss. The futures price (the delivery price under the contract) is then adjusted, in a process called marking to market, so that the amended contract again has a value of zero at the end of day one. The same process of paying capital gains, or collecting capital losses, occurs each trading day with a futures contract, as does the marking to market process needed to compensate for the payments. Thus in essence a futures contract is a 
series of forward contracts on which capital gains or losses are realized daily as they occur, rather than remaining unrealized until the delivery date.

\subsection{Recursive calculation of futures prices}

Let $H_{t}(j, T, M)$ be the futures price at time $t$, when the spot factor is $u^{j} R_{t}$, on a contract with delivery date $t$ written against a bill maturing at time $M$. On the delivery date, the futures price equals the value of the underlying instrument; cf. Cox, Ingersol, Ross [1981]. Therefore,

$$
H_{T}(j, T, M)=B_{T}(j, T, M) .
$$

In periods $t \in I_{0}^{T-1}$, the futures price is defined as $H_{t}(j, T, M)$. However, as with the underlying bills, the arguments $T$ and $M$ wil be suppressed whenever. no ambiguity results, and the futures price will usually be written $H_{t}(j)$; $t \in I_{0}^{T}$.

Under the perfect markets, zero arbitrage opportunities assumptions of this paper, futures prices satisfy the condition

$$
H_{t}(j)=p_{t} H_{t+1}(j+1)+q_{t} H_{t+1}(j-1) ; \quad t \in I_{1}^{T-1} ;
$$

and

$$
H_{T}(j)=B_{T}(j)=1 /\left[u^{j} R_{l}\right]^{M-T}, \quad j \in J_{T} .
$$

Then it follows immediately that

$$
H_{T}(T-2 k)=v^{2 k} H_{T}(T),
$$

where $v=v(T, M)=u^{M-T}$, and $k \in I_{0}^{T}$.

Taking (5.1.3) with $t=T-1$ and using (5.1.4) gives

$$
H_{T-1}(j)=\left[p_{T-1}+v^{2} q_{T-1}\right] \cdot H_{T}(j+1) .
$$

Similarly,

$$
H_{T-2}(j)=\left[p_{T-2}+v^{2} q_{T-2}\right] \cdot\left[p_{T-1}+v^{2} q_{T-1}\right] \cdot H_{T}(j+2),
$$

for all admissible $j$. It follows that

$$
\begin{gathered}
H_{t}(j)=v^{2} H_{t}(j+2), \quad \text { and } \\
H_{t}(j)=\left[p_{t}+v^{2} q_{t}\right] \cdot H_{t+1}(j+1),
\end{gathered}
$$

for $j \in J_{t}$ and for $t \in\{0,1, \ldots, T-1\}$.

Finally, setting $j=t$ and applying (5.1.7) recursively gives an explicit formula for the futures price at time zero:

$$
H_{0}(0)=B_{T}(T) \prod_{t=0}^{T-1}\left(p_{t}+v^{2} q_{t}\right) .
$$

The futures price depends on $M, T, B_{T}(T)$, and $u$, but not on $\left\{R_{t}\right\}$, $t \in I_{1}^{T-1}$.

It is also interesting to examine how the futures price behaves as a function of time to maturity. To discuss the maturity effect on its own, it is necessary to 
isolate it from the effect of interest rate change ${ }^{18}$. This is most easily achieved by first establishing how the futures price behaves at the maximum interest rate. Then it is easy to use this result to see how the futures price behaves at a given spot rate.

Proposition 5.1.1: The futures price $H_{t}(t)$ is a decreasing function of $t$. Inspection of (5.1.7) and (5.1.8) shows that

$$
H_{t}(t)>H_{t+1}(t+1)>H_{t+2}(t+2) \text {. }
$$

The next proposition uses (5.1.10) to determine the effect of a shortened maturity on the futures price when $j$ is held constant.

Proposition 5.1.2: Let the spot factor remain unchanged between periods. Then the ratio of futures prices decreases with time if and only if $M \geq M^{*}$, where

$$
M^{*}=T+\left\{\left[\ln \left(p_{t-2} p_{t-1} / q_{t-2} q_{t-1}\right)\right] / 2 \cdot \ln (u)\right\} .
$$

Proof: Use (5.1.7) and (5.1.8) to write

$$
H_{t}(j) / H_{t-2}(j)=v^{2} /\left[p_{t-2}+v^{2} q_{t-2}\right] \cdot\left[p_{t-1}+v^{2} q_{t-1}\right] .
$$

The behaviour of the ratio on the right hand side of (5.1.12) is revealed by defining

$$
x=v^{2}, \quad a=p_{t-2} \cdot p_{t-1}, \quad b=p_{t-2} \cdot q_{t-1}+p_{t-1} \cdot q_{t-2}, \quad c=q_{t-2} \cdot q_{t-1},
$$

and considering the equation

$$
x=a+b x+c x^{2} .
$$

Noting that $a+b+c=1$, rewrite the quadratic as

$$
[x-a / c][x-1]=0 .
$$

Given the values of $p_{t-1}, p_{t-2}, q_{t-1}$ and $q_{t-2}$ as assumed in (3.3.4), it follows that $a>c$. Thus when $v^{2}$ lies between unity and $a / c$, the ratio (5.1.12) is greater than unity, and for values of $v^{2}>a / c,(5.1 .12)$ is less than unity. Since $v^{2}$ is an increasing function of $M$, there is a critical value $M^{*}$ which determines whether (5.1.12) is increasing or decreasing in $t$.

Straightforward calculation shows $M^{*}$ is defined by (5.1.11). Note that $M^{*}$ is not necessarily an integer, as are $M$ and $T$.

18 Of course, it is possible to assess maturity and interest rate effects in combination. But for most empirical purposes one is interested in ceteris paribus predictions of the type next established. 


\subsection{Conditional variance of futures prices}

Conditional on a realization $H_{t}(j)$, the futures price at time $t+1$ is either

$$
\begin{aligned}
& H_{t+1}(j+1), \text { with probability } p, \text { or } \\
& H_{t+1}(j-1), \text { with probability } q .
\end{aligned}
$$

Using methods similar to those of Sections 3 and 4, the conditional variance of the futures prices is found to be

$$
V_{H, t}(j)=p q\left\{\left[v^{2}-1\right] \cdot\left[H_{t+1}(j+1)\right]\right\}^{2} .
$$

Then, using (5.1.8), (5.2.1) can be rewritten as

$$
V_{H, t}(j)=p q \cdot\left\{\left[v^{2}-1\right] \cdot\left[H_{t}(j)\right]\right\}^{2} /\left[p_{t}+v^{2} q_{t}\right]^{2} .
$$

To see the effect on $V_{H, t}(j)$ when $t$ increases while interest rates are held constant, recall from (5.1.7) that

$$
H_{t+2}(j)=v^{2} H_{t+2}(j+2) .
$$

Then by (5.1.3) and (5.2.2)

$$
V_{H, t}(j)=p q \cdot\left\{\left(v^{2}-1\right)\left[p_{t}+v^{2} q_{t}\right] H_{t+2}(j) / v^{2}\right\}^{2} .
$$

Then, whether (5.2.3) increases or decreases in $t$ depends on the behaviour of both $p_{t}+v^{2} q_{t}$ and $H_{t+2}(j)$, as well as on their relative sizes. Thus the change in $V_{H, t}(j)$ is in general ambiguous; cf. Propositon 5.1.2. by

Defining the conditional variance of the rate of change of the futures price

$$
V_{H, t}^{*}(j) \equiv V_{H, t}(j) /\left[H_{t}(j)\right]^{2},
$$

it follows immediately from (5.2.2) that

$$
V_{H, t}^{*}(j)=p q\left\{\left(v^{2}-1\right) /\left(p_{t}+v^{2} q_{t}\right)\right\}^{2},
$$

independent of $j$. Also, $V_{H, t}^{*}(j)$ increases in $t$ if and only if

$$
p_{t}+v^{2} q_{t}>p_{t+1}+v^{2} q_{t+1},
$$

as established in (3.3.5). In addition, considering successive terms in (5.2.4) shows that $V_{H, t}^{*}(j)$ is a convex function of $t$.

\subsection{Conditional risk premiums in futures prices}

Define the conditional risk premium in a futures price by

$$
P_{H, t}(j) \equiv E_{t}\left\{H_{t+1}(J)\right\}-H_{t}(j),
$$

where $E_{t}$ denotes the time $t$ conditional expectation of the time $t+1$ futures price, and $J \in\{j+1, j-1\}$.

Condition (5.3.1) can be rewritten

$$
P_{H, t}(j)=\left\{\left[p+v^{2} q\right]-\left[p_{t}+v^{2} q_{t}\right]\right\} \cdot H_{t}(j) /\left[p_{t}+v^{2} q_{t}\right] .
$$


The risk premium can also be expressed in terms of the rate of change of futures prices,

$$
P_{H, t}^{*}(j)=P_{H, t}(j) / H_{t}(j) .
$$

The risk premiums are positive in any period $t$ for which $p<p_{t}$, as shown in (3.5.4).

\subsection{Relations between conditional risk premiums and variance}

From (5.3.2) and (5.3.3)

$$
P_{H, t}^{*}(j) /\left[V_{H, t}^{*}(j)\right]^{1 / 2}=K_{H, t}^{*},
$$

where

$$
K_{H, t}^{*}=\left\{\left[p+u^{2[M-T]} q\right]-\left[p_{t}+u^{2[M-T]} q_{t}\right]\right\} /(p q)^{1 / 2}\left(u^{2[M-T]}-1\right) .
$$

After simplifying,

$$
K_{H, t}^{*}=\left(p_{t}-p\right) /(p q)^{1 / 2} .
$$

That is, the proportionality constant $K_{H, t}^{*}$ is the same for futures prices as for bond prices; cf. (3.6.2). The result is not surprising since a futures contract has the same rate of return behaviour as a series of investments in short term bonds, and since the rate of return behaviour on long bonds is related to the rate of return behaviour on short bonds by an absence of arbitrage profit opportunities.

\subsection{Relations between forward and futures prices}

The formulae for futures and forward prices permit explicit comparisons. Recall (4.1.6) and (5.1.9), from which the ratio $G_{0}(0) / H_{0}(0)$ can readily be calculated. In addition, by using (3.2.3), forming the ratio $H_{0}(0, T, M) / B_{0}(0, T, M)$, recalling that $u>1$, and that

$$
B_{0}(0, T, T)=1 / R_{0} \cdot u R_{1} \cdot \ldots \cdot u^{T-1} R_{T-1},
$$

it is easy to see that

$$
G_{0}(0, T, M)=B_{0}(0, T, M) / B_{0}(0, T, T)>H_{0}(0, T, M) .
$$

The last condition is a special case of COX - INGERSOLL - Ross Propostion 9 [1986, pp. 331-332].

\section{CONCLUSIONS}

This paper has presented a discrete time model for consistently pricing treasury bills as well as the futures and forward contracts written against them. For each instrument, the paper also finds formulae the conditional variance of return, the risk premium, and the ratio of conditional variance to conditional risk premium. The formulae are consistent with observed time zero data, and the evolution of future interest rates is less restricted than in other, similar 
models. The paper also shows that single factor models imply relationships between the different factors affecting the term structure's evolution, and that other similar models have not recognized the dependencies created by these restrictions. Finally, we resolve a problem left open in HJM [1990a] by finding conditions under which the martingale probabilities will be unique.

\section{APPENDIX I \\ THE INDUCTIVE FORMULA ${ }^{19}$}

Let $B_{t}(T)$ be a random variable reflecting the time $t$ price of a zero coupon bond maturing at time $T \geq t$. In this notation, unlike that of the body of the paper, the dependence of the bond price on the interest rate is left implicit. Also, let

$$
U_{t+1}=\begin{aligned}
u U_{t} ; & \text { with probability } p \\
u^{-1} U_{t} ; & \text { with probability }(1-p)
\end{aligned}
$$

Theorem: The value of a zero coupon bond is given by:

$$
B_{t}(T)=U_{t}^{-(T-t)} \frac{B_{0}(T)}{B_{0}(t)} \prod_{s=t}^{T-1}\left\{p_{s} u^{-(T-s-1)}+\left(1-p_{s}\right) u^{T-s-1}\right\} .
$$

Proof: Fix $T$ and proceed using backward induction on $t$. Equation (A.1) is trivially true for $t=T$, using the usual convention that an empty product equals unity. For $t<T$, the definition of the martingale probability $p_{t}$ means the expected return factor $S_{t}$ on a bill is given by

$$
E^{*}\left\{B_{t+1}(T)\right\}=E^{*}\left\{S_{t} B_{t}(T)\right\},
$$

where $S_{t}$ is defined in (2.2.2) and the asterisk denotes expectation under the martingale. But

$$
S_{t}=U_{t} R_{t}=U_{t}\left\{B_{0}(t) / B_{0}(t+1)\right\} .
$$

Then assuming under the induction hypothesis that (A.1) holds for $t$,

$$
\text { (A.4) } \begin{aligned}
E^{*}\left\{B_{t+1}(T)\right\}= & \frac{B_{0}(T)}{B_{0}(t+1)} \prod_{s=t+1}^{T-1}\left\{p_{s} u^{-(T-s-1)}\right. \\
& \left.+\left(1-p_{s}\right) u^{T-s-1}\right\} E^{*}\left\{U_{t+1}^{-(T-t-1)}\right\} .
\end{aligned}
$$

from which it follows that, since the last term on the right hand side is an

19 We are indebted to a referee for providing the derivation and interpretation given in this Appendix. 
expectation given information at time $t$ :

$$
\begin{aligned}
\mathrm{E}^{*}\left\{U_{t+1}^{-(T-t-1)}\right\} & =U_{t}^{-(T-t-1)} E^{*}\left[U_{t} / U_{t+1}\right]^{T-t-1} \\
& =U_{t}^{-(T-t-1)}\left\{p_{t} u^{-(T-t-1)}+\left(1-p_{t}\right) u^{(T-t-1)}\right\} .
\end{aligned}
$$

Equation (A.1) then follows.

In addition, the martingale probabilities can be obtained by equating the induction based prices to the known prices at time 0 , producing the following specialized version of (A.1):

$$
1=\prod_{s=0}^{T}\left\{p_{s} u^{-(T-s)}+\left(1-p_{s}\right) u^{T-s}\right\}
$$

from which $p_{t}=u^{2 t+1} /\left(1+u^{2 t+1}\right)$ can be derived.

\section{REFERENCES}

BLACK, F, (1976) The pricing of commodity contracts. Journal of Financial Economics 3, 167179.

Black, F., Derman, E. and Toy, W. (1990) A one-factor model of interest rates and its application to treasury bill options. Financial Analysts Journal, January-February, 33-39.

BLIss, R. R. and RonN, E. I. (1989) Arbitrage-based estimation of nonstationary shifts in the term structure of interest rates. Journal of Finance 44, 591-610.

BoYLE, P. B. (1989) The quality option and timing option in futures contracts. Journal of Finance 44, $101-113$.

Cox, J.C., Ingersoll, J. and Ross S. A. (1981) The relation between forward prices and futures prices. Journal of Financial Economics 9, 321-346.

Cox, J.C. and Rubinstein, M. (1985) Options Markets, Englewood Cliffs, N.J. Prentice-Hall.

Cox, J.C., Ross, S. A. and Rubinstein M. (1979) Option pricing: a simplified approach. Journal of Financial Economics 7, 229-263.

Dybvig, P.H. (1989) Bond and bond option pricing based on the current term structure, manuscript.

ENGLE, R.F. (1982) Autoregressive conditional heteroscedasticity with estimates of the variance of United Kingdom inflation. Econometrica 50, 987-1007.

ENGLe, R. F., LiLien, D. M. and Robins, R.P. (1987) Estimating time varying risk premia in the term structure. Econometrica 55, 391-407.

FrENCH, K. R. (1981) A comparison of futures and forward prices. Journal of Financial Economics $12,311-342$.

GAY, G.D. and MANASTER, S. (1984) The quality option implicit in futures contracts. Journal of Financial Economics 13, 353-370.

Heath, D., JarRow, R. and Morton, A. (1992) "Bond pricing and the term structure of interest rates". Econometrica 60, 77-105.

Heath, D., Jarrow, R. and Morton, A. (1990a) "Bond Pricing and the Term Structure of Interest Rates: A Discrete Time Approximation". Journal of Financial and Quantitative Analysis 25, 419-440.

Heath, D., Jarrow, R. and Morton A. (1990b) "Contingent Claim Valuation with a Random Evolution of Interest Rates". The Review of Futures Markets 9, 54-76.

HEMLER, M. L. The quality delivery option in treasury bond futures contracts. Journal of Finance 45, $1565-1586$.

Ho, T.S.Y. and LEE, S. (1986) Term structure movements and pricing interest rate contingent claims. Journal of Finance 41, 1011-1029.

Huang, C-f and Litzenberger, R.H. (1988) Foundations for financial economics. NorthHolland.

Hull, J. and White A. (1989) "Pricing interest-rate sensitive securities". University of Toronto Graduate School of Management Working Paper, presented to Northern Finance Association, Ottawa, 1989. 
Hull, J. and WhITE, A. (1990) One factor interest-rate models and the valuation of interest-rate derivative securities. University of Toronto Working Paper.

JACOBs, R. L. and Jones, R.A. (1980) The treasury bill futures market. Journal of Political Economy 88, 699-721.

JAMSHIDIAN, F. (1989) An exact bond option formula. Journal of Finance 44, 205-209.

JAMSHIDIAN, F. (1990) Bond and option evaluation in the Gaussian interest model. Research in Finance..

JAMSHIDIAN, F. (1990) The preference free determination of bond and option prices from the spot interest rate. In: Advances in Futures and Options Research 4, 51-67.

JAMSHIDIAN, F. (1991) Forward induction and construction of yield curve diffusion models. Journal of Fixed Income, 62-74.

Jarrow, R.A. and OldField, G.S. (1981) Forward contracts and futures contracts. Journal of Financial Economics 9, 373-382.

KANE, A. and MARCus, A. (1986) Valuation and optimal exercise of the wild card option in the treasury bond futures market. Journal of Finance 41, 195-207.

Kishimoto, N. (1989) Pricing contingent claims under interest rate and asset price risk. Journal of. Finance 44, 571-590.

Morgan, I. G. and Neave, E.H. (1989) A discrete time forward and futures pricing model. Proceedings, First AFIR International Conference, Paris, 1989.

Morgan, I.G. and NeAve, E.H. (1991) "A mean reverting process for pricing treasury bills and futures contracts". Second AFIR International Colloquium, Brighton, vol I, 237-266.

Morgan, I.G. and Neave, E.H. (1992) "Time series properties of futures prices for pure discount bonds", to be presented to Western Finance Association Meetings, San Francisco.

NeweY, W.K. (1985) Maximum likelihood specification testing and conditional moment tests. Econometrica 53, 1047-1070.

Pagan, A. R. and Sabau, H.C.L. (1987) Consistency test for heteroskedastic and risk models, manuscript.

Pedersen, H.W., Shiu, E. S. W. and Thorlacius, A. E. (1989) Arbitrage-free pricing of interestrate contingent claims. Transactions of the Society of Actuaries 41, 231-265.

PoItras, G. (1988) "Hedging Canadian Treasury Bill Positions with US Money Market Futures Contracts". Review of Futures Markets 7, 176-191.

Richard, S.F. and Sundaresan, M. (1981) A continuous time equilibrium model of forward prices and futures prices in a multigood economy. Journal of Financial Economics 9, 347-372.

RitCHKEN, P. and BOENAWAN K. (1990) On arbitrage free pricing of interest rate contingent claims: a note. Journal of Finance 45, 259-264.

Ritchien, P. and Sankarasubramanian, L. (1990) On valuing complex interest rate claims. The Journal of Futures Markets 10, 443-455.

TAUCHEN, G.E. (1985) Diagnostic testing and evaluation of maximum likelihood models. Journal of Econometrics 30, 415443.

Turnbull, S. M. and Milne, F. (1991) A simple approach to interest-rate option pricing. Review of Financial Studies 4, 87-120.

I. G. Morgan and E. H. Neave

Queen's University School of Business, Kingston, Ontario K7K 3 N6. 